\title{
Oliver syndrome
}

INSERM

\section{Source}

INSERM. (1999). Orphanet: an online rare disease and orphan drug data base. Oliver

syndrome. ORPHA:2920

Oliver syndrome is a very rare syndrome characterized by intellectual deficit, postaxial polydactyly, and epilepsy. 